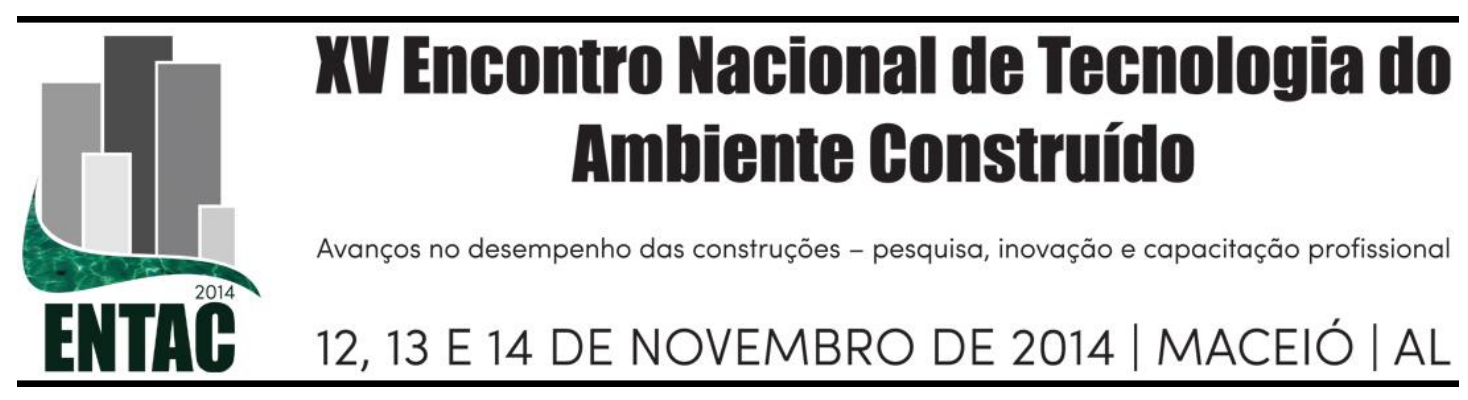

\title{
TIPOLOGIAS HABITACIONAIS, DEMANDAS DA POPULAÇÃO E IMPLICAÇÕES NO PROCESSO PROJETUAL
}

\author{
LACERDA, Leandro Ismael de Azevedo (1); PASSOS, Luciana Andrade dos (2); \\ ALONSO, Patrícia (3)
}

(1) UFPB, e-mail: leo.aslemn@gmail.com, (2) UFPB, e-mail: lucianadospassos@hotmail.com, (3)

UFPB, e-mail: pataalonso@gmail.com

\begin{abstract}
RESUMO
No âmbito das ações do Poder Público, a exemplo do programa Minha Casa, Minha Vida, a adoção de tipologias arquitetônicas, direcionadas à política habitacional para atender à demanda no meio urbano, tem apresentado diferentes conflitos quanto às necessidades da população atendida. $\mathrm{O}$ objetivo desta pesquisa é identificar os principais aspectos de divergência entre tipologias concebidas pelo Poder Público e as demandas da população, no que se refere à concepção da unidade e do conjunto habitacional no Município de João Pessoa (PB). Especificamente, este estudo busca: (1) identificar as principais divergências apontadas pela população contemplada; (2) analisar, comparativamente, as demandas da população e as tipologias estudadas. Para tanto, adotou-se uma pesquisa-ação, por meio da participação em debates, gravados em vídeos e registrados em atas, para posterior análise de conteúdo desse material decorrente das reuniões realizadas com a presença de líderes comunitários e integrantes da Secretaria Municipal de Habitação (SEMHAB/PMJP), ocorridas entre os meses de Março e Abril de 2013, durante o Programa de Extensão Universitária (PROEXT/2013), financiado pelo Ministério da Educação, intitulado Estratégias Integradas de Reabilitação para Habitação de Interesse Social na área central de João Pessoa $\mathrm{PB}$, vinculado ao Departamento de Arquitetura (DA/CT/UFPB). Os resultados apresentaram o descompasso entre as demandas, as necessidades do público e a concretização destas, expressas na tipologia do projeto. Verificou-se a inadequação da tipologia quanto à localização, implantação, dimensionamento, uso, cultura, inflexibilidade, padronização excessiva e inadequação dos espaços criados à dinâmica dos moradores. Portanto, ratifica-se a necessidade de se envolver as entidades de representação no processo projetual participativo, como atividade necessária. A adoção de iniciativas de participação da população deve-se não apenas se destinar à legitimação do projeto, mas sim, incorporar as demandas daqueles que deverão usufruir do projeto - não apenas quando o programa já se encontra em fase de conclusão. Logo, é importante a inserção da comunidade em todo o processo projetual, para integração de interesses e avaliação contínua, com o objetivo de elaborar, de forma conjunta, uma tipologia habitacional adequada às necessidades e especificidades do público.
\end{abstract}

Palavras-chave: Tipologia Habitacional, Participação da População, Processo Projetual.

\begin{abstract}
Among the many actions of the government, such as the Minha Casa, Minha Vida, the adoption of architectural typologies, focused on solving the demand for housing inside urban areas through housing policies, has shown different clashes when it comes to the needs of the target audience. The main goal of this research is to identify the main aspects of divergence between the architectural typologies conceived by the government and the needs of the target audience for such buildings, regarding the conception of both the unit and the housing group inside the city of João Pessoa (PB). Specifically, this study aims to: (1) identify the main divergences indicated by the covered population; (2) analyze, comparatively, the specific needs of such population and its relationship with the adopted typologies. To do so, an action research was executed, based on the participation through discussions, registered in videos and written records for subsequent content analysis, those collected from meetings held with social and community representatives, and members of the Housing Department of the Municipal Office of João Pessoa
\end{abstract}


(SEMHAB/PMJP), that took place between the months of March and April of 2013, bounded to the Education and Public outreach program entitled Estratégias Integradas de Reabilitação para Habitação de Interesse Social na area central de João Pessoa - PB, promoted by the Architecture Department of Federal University of Paraíba (DA/CT/UFPB). The results have shown a gap between the specific demands and needs of the covered population and its concrete realization: the architectural typology, seen as inappropriate in aspects such as location, implantation, design, uses, culture, inflexibility and excessive standardization, as well as the rooms being inadequate to the many aspects of the users' spatial dynamics. Therefore, the need to engage the many entities of representation inside the participation process, being understood as a necessary action is confirmed. The adoption of such initiatives for user participation should not only be directed to the final stages of the process, but rather incorporate the demands of those who should be benefited from the project itself - not just when the program is already nearing completion. It is then important to include the community throughout the design process, to integrate interests and continuous assessment, airing to develop, together, an adequate housing typology to the needs and specificities of the public.

Keywords: Housing Typology, Community participation, Design Process.

\section{INTRODUÇÃ̃O}

A adoção de tipologias arquitetônicas habitacionais destinadas à demanda no meio urbano tem gerado questionamentos quanto ao seu alcance para o atendimento das reais necessidades da população de baixa renda beneficiada pelos programadas governamentais. Uma complexidade de fatores está relacionada a esse embate, sendo, um deles, o processo projetual - foco de reflexão deste artigo.

O processo projetual é visto, frequentemente, pelos profissionais e técnicos de governo, como etapas sucessivas de concepção e desenvolvimento (racional e linear) de um produto (o projeto) cuja origem é o programa arquitetônico. O usuário é interpretado enquanto agente passivo no processo projetual, responsável apenas pelo subsequente usufruto do produto desenvolvido.

Essa "hegemonia" da atuação do arquiteto na formulação das soluções projetuais, aliada a não observância e incorporação das demandas e necessidades dos usuários à proposta, configuram-se enquanto geratrizes das diversas inadequações da tipologia projetual às necessidades e demandas específicas da população, provocando apropriações espaciais com funções distintas, e por vezes contrárias àquelas idealizadas no projeto.

O Programa de Extensão Universitária (PROEXT/2013), financiado pelo Ministério da Educação, intitulado Estratégias Integradas de Reabilitação para Habitação de Interesse Social na área central de João Pessoa - PB, vinculado ao Departamento de Arquitetura (DA/CT/UFPB) teve como principal objetivo estabelecer estratégias integradas de políticas de reabilitação urbana para o centro histórico de João Pessoa (PB). No âmbito de suas atividades, o Programa revelou debates entre lideranças da sociedade civil, técnicos municipais, discentes e docentes relevantes para o estudo das implicações da observância das demandas da população no processo projetual.

Dessa maneira, objetiva-se com este artigo a identificação dos principais aspectos de divergência entre as tipologias habitacionais adotadas pelo Poder Público e as demandas da população beneficiada, mediante análise tanto da unidade habitacional isolada, quanto do conjunto habitacional. Propõe-se, especificamente, a identificação das principais divergências pelos usuários e a análise comparativa entre as demandas da população e a tipologia habitacional implementada.

Adotou-se uma pesquisa ação, apoiada na realização de reuniões integradas, contando com a presença de líderes comunitários e técnicos da Secretaria Municipal de Habitação 
(SEMHAB/JP), ocorridas entre os meses de Março e Abril de 2013 e vinculadas ao Programa (PROEXT/DA/UFPB/2013).

Nas reuniões destinadas à apresentação do Programa para os representantes da sociedade civil e técnicos municipais, o debate foi registrado em vídeo e atas. A análise de conteúdo foi realizada a partir dos dados coletados no áudio e no texto. As categorias dessa análise dos dados correspondem: (i) as insatisfações, (ii) os pontos de divergência, (iii) e as diretrizes para melhoria da tipologia arquitetônica dos conjuntos habitacionais de João Pessoa.

A revisão bibliográfica fundamentou tanto a compreensão das diferentes abordagens e experiências sobre o processo projetual participativo e a adoção de partidos conflitantes quanto às necessidades da população. A coleta e registro dos dados obtidos nos debates; a sistematização das informações; análise dos dados recolhidos atentando para as variáveis anteriormente definidas; subsidiaram a descrição dos resultados obtidos.

\section{TIPOLOGIAS HABITACIONAIS: ADOÇÃO DE PARTIDO EM CONFLITO COM AS NECESSIDADES DA POPULAÇÃO ATENDIDA}

O estudo das boas-práticas arquitetônicas, do ponto de vista tipológico, são amplamente estudadas na academia, assim como, discutidas nas políticas públicas. Contudo, analisam-se pouco as "inadequações" das soluções projetuais (ALCÂNTARA, MONTEIRO, 2010). Autores, como Freitas (2004), Alcântara e Monteiro (2010) e Borba (2014), ao se debruçarem sob a avaliação dos conjuntos habitacionais populares, convergem para a verificação de inúmeras insatisfações quanto à tipologia habitacional e à dinâmica social dos moradores inseridos em locais e realidades distintas.

Nessas pesquisas, o espaço é entendido como elemento diretamente atrelado à dinâmica, na medida em que condiciona, sugere ou dificulta a realização de determinada atividade, e oferece possibilidades de apropriação do espaço construído pelo usuário, como trata Malard et al (2002). Sendo assim, o estudo do espaço construído é caraterizado como recurso fundamental ao entendimento da adequação das soluções projetuais adotadas, já que suas apropriações refletem diretamente as intenções e anseios da população que delas usufrui.

Alcântara e Monteiro (2010) destacam, entre as modificações e apropriações analisadas, àquelas voltadas à aproximação da tipologia à dinâmica dos moradores, tais como a abertura de terraços, varandas, portas e janelas voltadas à rua, exprimindo o desejo de aproximação da unidade habitacional ao espaço público. Assim a sociabilidade pode ser incorporada no projeto de conjunto habitacional e, para tanto, isso depende diretamente da aproximação entre o morador e o espaço público, reforçando, de um lado a noção de comunidade, com a ampliação e construção de novos cômodos, relacionada ao crescimento do núcleo familiar, ou, por outro lado, induzindo a negação do espaço proposto, e, consequentemente, o abandono e a depredação de espaços e bens coletivos, a exemplo de centros comunitários, equipamentos e mobiliário urbano.

Revelam-se também diversos parâmetros de insatisfação dos usuários quanto a localização da habitação na malha urbana. De acordo com Freitas (2004), os conjuntos são implantados em locais distantes, ermos, geralmente em áreas periféricas da cidade, completamente isolados da dinâmica dos moradores, acarretando dificuldades no acesso a equipamentos e serviços urbanos e um gasto, para a provisão de infraestrutura urbana, muitas vezes superior àquele necessário à recuperação de moradias em áreas 
deterioradas; além da ausência de equipamentos e espaços de lazer dos conjuntos habitacionais.

Outro aspecto importante trata da dificuldade de arcar financeiramente com a nova habitação, ocasionado pela autonomia da unidade habitacional e novas instalações, que apesar de apontadas enquanto benefício em relação à situação anterior dos moradores, geram novas despesas, que aliadas à suspensão de benefícios de assistência por diversas entidades, principalmente religiosas (ALCANTARA \& MONTEIRO, 2010) fomentam grande dificuldade, ou, por vezes, torna-se impraticável, a adaptação da população de baixa renda à nova realidade.

$\mathrm{Na}$ literatura acadêmica ressalta-se também o caráter "estático" do arranjo espacial empregado no conjunto, onde a impossibilidade de alterações efetivas tanto na moradia quanto no arranjo espacial, intensifica a problemática decorrente da inadequação das dimensões e do programa dos apartamentos à dinâmica social da população de baixa renda. O desenho do projeto urbanístico proposto, apresentando ruas ortogonais, grandes corredores e por vezes a distribuição inadequada dos equipamentos, também prejudica diretamente a apropriação do espaço, derivado da não-observância das práticas sociais da população e a incorporação delas ao projeto proposto.

A participação da população no desenvolvimento da proposta, em conjunto com o Poder Público, no entendimento de Alcântara e Monteiro (2010), sinaliza para a oportunidade de consolidar a realização do projeto social, com o objetivo de garantir o respeito à diversidade de hábitos, atitudes e culturas específicas, para criar as condições necessárias à compreensão e valorização do espaço e da cidadania.

Logo, a incumbência do projetista deve ser de conhecer as variáveis e os problemas associados à tipologia arquitetônica, verificando as formas de inserção da população nas decisões sobre o desenvolvimento da proposta, para - com a incorporação do olhar do morador - formular uma tipologia arquitetônica direcionada à integração social e satisfação do usuário com o lugar onde habita.

\section{PROCESSO PROJETUAL PARTICIPATIVO}

O processo projetual, como trata Boutinet (2002 apud DUARTE et al, 2008), pode ser entendido como um processo de antecipação e idealização de uma realidade desejada, com a solução projetual desenvolvida sob a premissa da concretização do abstrato concebido.

Os questionamentos e discussões sobre o atual modelo de processo projetual, e o debate sobre a inserção da população nas diferentes fases do desenvolvimento do projeto arquitetônico surgem, como trata Jensen (2006), da mudança de perspectiva quanto ao papel das edificações e do usuário na dinâmica do espaço arquitetônico, sendo destacada a necessidade de efetivar a proposta de um processo projetual participativo, onde a tipologia da edificação responda e esteja sujeita à ação de diversos atores.

Com isso, o edifício passa a não ser interpretado exclusivamente como a mera expressão construída e materialização física de uma ideia, configurando-se como um elemento passivo e estático, mas sim como um objeto, com a incumbência de prover suporte físico ao processo de apropriação do espaço, favorecendo ou dificultando a realização de determinada atividade.

O rompimento do paradigma sobre o papel do usuário também condicionou a valorização da participação popular como meio de garantia da qualidade dos projetos desenvolvidos, sejam arquitetônicos ou não. Como aponta Duarte et al (2008), a 
literatura referente ao design, por exemplo, antes considerava que as fontes de inovação estariam presentes exclusivamente no interior das empresas responsáveis pela fabricação dos produtos, sendo raramente observada a dialética entre a inovação tecnológica e os usuários. Entretanto, Granath (2001) ressalta que, no contexto do que é caracterizado como a era da informação, os olhares voltam-se ao reconhecimento da dedicação e capacidade de formulação das soluções projetuais dos usuários, não mais submetidos à ação dos agentes responsáveis pelo projeto, mas capazes também de projetar, reformular e gerenciar os recursos de produção do espaço em que ocupam.

Nesse sentido, no caso do processo projetual arquitetônico, este se distancia da imagem de um processo simples, linear e elaborado por uma equipe de técnicos específicos, de atuação isolada e passa a ser valorizada a partir de uma perspectiva enquanto processo dinâmico e interativo, incorporando as necessidades e cultura dos usuários às diferentes etapas da construção, e gerando por consequência, um projeto de maior identificação com o público.

Entretanto, para entender a participação do coletivo na elaboração do objeto arquitetônico, que será apropriado, por vezes, por milhares de usuários distintos, faz-se necessário o estudo dos diversos níveis de participação, como aqueles abordados por Granath (2001), relacionados às diferentes relações entre usuário e objeto: (i) pela participação mediada pelo projeto: onde a proposta é desenvolvida de tal maneira a condicionar a participação dos usuários nas intervenções no projeto; (ii) e a participação no projeto: onde os usuários se inserem e assumem diversas funções durante a totalidade do processo projetual; (iii) e relações de representatividade e contato com o público, mediante participação direta, onde o usuário participa ativa e individualmente no desenvolvimento da proposta, que comumente gera dificuldades quanto à participação pela diversidade de características e opiniões de cada integrante; (iv) ou participação indireta, onde os interesses da comunidade são defendidos pela ação de um terceiro, representante político ou social, e a eficácia da participação é determinada pelo grau de representação cumprido pela entidade.

Uma das questões metodológicas abordadas por diversos autores, após a definição dos parâmetros de interação e representação do usuário perante o projeto, é o momento em que essa participação deve ser inserida no processo projetual, sendo questionada a adequação das intervenções e consequências destas ao produto.

A participação dos usuários no processo de projeto desde os estágios iniciais têm sido tratada como de grande contribuição à qualidade do produto desenvolvido. Nesta situação, os usuários podem envolver-se a tal ponto de influenciar diretamente as definições iniciais da proposta, sendo possível a garantia de que todo o processo gire em torno de diretrizes definidas pela própria população. A abertura à participação é de fundamental importância uma vez pode garantir a elaboração de uma proposta mais próxima ao atendimento das necessidades específicas dos usuários. As experiências de Jensen (2006) demonstraram que, nos projetos da tipologia habitacional onde a população participara ativamente das definições iniciais, a satisfação geral com a tipologia e para com o próprio processo de relocação fora bastante significativa, justamente pelo processo de preparação da sociedade para a nova realidade.

É destacável também, a participação da população nas etapas de execução das tipologias, pela realização de mutirões junto à assistência técnica, pois como aponta Malard et al (2002), a experiência dessa forma de construção se mostra significativa, pela possibilidade de gestão administrativa e financeira do empreendimento, que, 
construído pelo esforço comunitário, apresenta melhor possibilidade de identificação da sociedade para com o espaço que por aqueles construídos por empreiteiras.

Contudo, ressaltam-se algumas dificuldades quanto à viabilização da participação dos usuários nas etapas iniciais do processo, quanto ao não-reconhecimento das reivindicações, ou a rejeição de possíveis propostas de alterações que modifiquem bruscamente a proposta dos técnicos ou requisitem a adoção de novas decisões políticas, exercendo impacto econômico ou de tempo de projeto na proposta desenvolvida. No entanto, como trata Granath (2001), o problema conceitual onde as manifestações dos usuários são vistas como intervenções negativas sob o ponto de vista dos profissionais e representantes do poder público envolvidos poderia ser minimizado se as reivindicações pudessem ser consideradas desde o início, possibilitando que as intervenções sejam debatidas antes e durante o desenvolvimento conjunto de um mesmo objeto.

O fato que ocorre com frequência, segundo Alcântara e Monteiro (2010), é que os moradores são consultados posteriormente, apenas para a legitimação da proposta, quando esta já está prestes a ser posta em prática, acarretando situações onde os moradores são questionados apenas sobre a preferência quanto à aplicação de cores e elementos decorativos nas tipologias.

Por outro lado, experiências como as realizadas por Del Rio et al (2000) apontam para a possibilidade de viabilizar a participação dos usuários, tanto em contato direto entre público e profissionais envolvidos, quanto por representantes, através de estratégias metodológicas tais como, o levantamento de desejos e expectativas dos usuários, por meio de entrevistas ou questionários, direcionadas à identificação das principais necessidades para com o espaço; o levantamento do desempenho físico-espacial, onde se identificam os principais graus de funcionalidade, segurança, adequação e qualidade do edifício; e debates, contando com a presença de diferentes entidades, onde podem ser extraídas diversas sugestões e diretrizes para o projeto.

Portanto, ratifica-se que a adoção de métodos participativos ao processo de projeto podem afetar positivamente os resultados. Como aponta Granath (2001), é necessária a conscientização do arquiteto para com a valorização das contribuições do olhar "leigo" para o que está sendo desenvolvido, com o objetivo de assegurar a todos os envolvidos a democratização da informação, consolidando assim um processo voltado muito mais à dinâmica do aprendizado, onde todas as partes, através de contribuições distintas, podem gerar uma solução adequada à maioria dos interesses, destacando-se que "sem nunca abrir mão do saber específico do arquiteto, a atividade de projeto pode constituir um processo democrático e construtivo ao incluir a participação dos usuários, gerando ambientes não apenas melhores e mais responsivos, mas também esteticamente agradáveis". (DEL RIO et al, 2000:112)

\section{CONFLITOS RELACIONADOS AOS CONJUNTOS HABITACIONAIS DO PROGRAMA MINHA CASA MINHA VIDA EM JOÃO PESSOA - PB}

A Lei $n^{\circ} 11.977$, de 07 de junho de 2009 oficializou a criação do programa habitacional anteriormente adotado pelo Governo Federal, durante a gestão de Luiz Inácio Lula da Silva, desde março de 2009, tendo sido responsável, segundo dados da Caixa Econômica Federal, pela provisão de milhões de unidades habitacionais à população de baixa renda, fazendo-se necessária uma avaliação qualitativa dos projetos, em contraponto ao elevado número de habitações implementadas. 
O Município de João Pessoa, também se configura como beneficiário do programa, sendo alvo da ação habitacional promovida, que consolidou a construção de diversos conjuntos e unidades habitacionais em sua área urbana.

Reportando-se à maior possibilidade de interpretação da dinâmica espacial dos conjuntos habitacionais pelo olhar do usuário, e pelo entendimento de líderes comunitários e representantes de movimentos sociais enquanto canais de representação dos interesses da coletividade, foi possível, por meio da análise do discurso dos envolvidos nos debates das reuniões do PROEXT 2013, verificar diversas inadequações, tanto na esfera da tipologia da unidade habitacional isolada, quanto do conjunto urbano das edificações.

A primeira das inadequações refere-se à incompatibilidade da unidade habitacional e/ou do conjunto com as necessidades vinculadas às atividades de subsistência, desenvolvidas pelos usuários. De forma geral, sem citar um caso de conjunto habitacional específico, foi mencionado pela liderança comunitária, o problema ocasionado pela inexistência de espaço no projeto com o fim de guardar o material de trabalho:

É preciso que a gente tenha um lugar pra guardar os objetos de trabalho, para que possam fazer o que precisam no dia-a-dia do comércio aqui do Centro, porque o que a gente vê hoje em dia são as pessoas vindo pra morar nas casas, e acabam vendendo as casas por falta, muitas vezes, de infraestrutura, e voltam para o lugar onde estavam. (Líder comunitário, representante do MAM - Movimento de Ajuda Mútua, em 13 de Março de 2013)

A intervenção do líder aponta, de imediato, para a impossibilidade dos espaços de moradia comportar o material de trabalho do residente, como consequência do dimensionamento inadequado dos cômodos. Ainda, é sinalizada, pela menção ao processo de abandono das habitações, a dificuldade de adequação das famílias à realidade do conjunto habitacional; seja por efeito do processo de relocação, quando a população não é preparada para a nova realidade no decorrer do processo; ou enquanto corolário à perda da qualidade do espaço devido à implantação e localização inadequadas dos conjuntos que, geralmente implantados em locais periféricos, não possuem a infraestrutura e equipamentos necessários à garantia da qualidade urbana. Entende-se ainda que este padrão de implantação prejudica e até anula a possibilidade do morador em exercer sua forma de geração de renda; a exemplo da dificuldade de acesso aos pontos de comércio, quando exercem este ofício, o que ressalta que a não observância destas variáveis no desenvolvimento do projeto pode prejudicar completamente a subsistência do núcleo familiar.

Vale registrar que a dinâmica econômica tem aspecto de destaque nessa faixa de renda, e essa baixa flexibilidade de mudanças espaciais dificulta o empreendedorismo ou mesmo o armazenamento do material de trabalho (como, por exemplo, o do público de ambulantes).

Além de questões relacionadas às atividades econômicas informais e sua não observância, além da desconsideração dos mecanismos de geração de renda, existem aqueles aspectos relacionados às questões socioculturais. Tratam-se dos mecanismos de viabilizar a convivência de grande número de usuários em pequenos espaços privados. Ademais, são atividades que se apresentam com uma diversidade de fins, sejam de higiene ou de modos de "criação" e educação infantil.

A gente precisa de um lugar pra lavar roupa, aqui a gente tem famílias enormes, cada uma com um costume diferente. No Nordeste a gente tá acostumado a lavar a roupa em casa; quando nasce um menino, a gente estende 
uma rede, como a gente vai fazer isso num apartamento desses?! Eles precisam entender isso, e construir a casa pensando em quem vai morar nela, porque como existe aqui: casa com catorze pessoas? Não existe dignidade pra ninguém. (Líder comunitária, representante da ACIS - Associação de Cidadania e Inclusão Social)

Assim, verifica-se a inadequação da tipologia habitacional quanto à cultura local de apropriação dos espaços, que demanda a adoção de soluções de dimensionamento, usos e organização espacial específicas, de acordo com as diferentes manifestações da dialética entre usuário e espaço construído. A uniformização das soluções quanto ao número de integrantes da família e, o consequente subdimensionamento do cadastro dos moradores subdimensionado limitam a abrangência das soluções e dificultam a garantia da qualidade do espaço ao morador, sendo necessário o entendimento da tipologia construtiva enquanto elemento dinâmico, com a adoção de soluções diversificadas e em correspondência com o núcleo familiar.

As reinvindicações de inserção das demandas dos usuários não são apenas no âmbito habitacional, solicita-se a atenção ao morador também no projeto urbanístico, uma vez que parece evidente a inadequabilidade do espaço interno e externo de conjunto habitacional. As lideranças enfatizaram que são desconsideradas as variáveis de arborização e conforto térmico, além da não-implantação de mobiliário urbano, gerando espaços sem qualquer tratamento paisagístico.

\begin{abstract}
A gente tem interesse é que se comece a pensar no projeto antes da própria obra, já que hoje em dia, no próprio Minha Casa, Minha Vida, só se faz o cadastro da família quando a obra está em 40\%. Por exemplo, no Irmã Dulce (conjunto habitacional localizado no bairro Colinas do Sul, no município de João Pessoa), que é um empreendimento grande, com mais de mil unidades, se foi pensado apenas na casa, ninguém pensou nas escolas, no posto de saúde; ninguém pensou nem em uma árvore, é um deserto, o calor é insuportável! (Líder comunitária, representante da ACIS - Associação de Cidadania e Inclusão Social, em 13 de Março de 2013)
\end{abstract}

As inquietações também podem ser encontradas na intervenção do técnico municipal da Secretaria de Habitação. Para ele, a dificuldade do processo projetual também se apresenta antes mesmo do início da concepção. A caracterização do usuário não pode se efetivar uma vez que a estrutura de financiamento e gestão do Programa Federal permite a construção do conjunto habitacional sem identificação do perfil do usuário.

Outro problema é a própria gestão do programa Minha Casa Minha Vida, já que hoje para conseguir financiamento, só por ele. E o programa, infelizmente, funciona dessa forma: primeiro se constrói, pra só depois saber quem vai morar lá, por cadastro, sorteio. Como você vai fazer um projeto sem saber pra quem é? É um projeto padrão, mas você vai doar a quem? (Técnico da Secretaria Municipal de Habitação - SEMHAB/JP, em 13 de Março de 2013)

Logo, o usuário é considerado como integrante de um grupo (categorizados pelo número de pessoas por famílias), com as mesmas necessidades e pouca especificidade quanto ao apoio à geração de renda que já desenvolve. Portanto, os dados preliminares necessários para iniciar a etapa de uma concepção do processo projetual de conjunto habitacional, são incompletos ou inadequadamente universais ou generalistas.

No entanto, é citada, também no discurso dos técnicos, a dificuldade dos responsáveis pelo projeto e do próprio Poder Público em implementar uma tipologia habitacional diferenciada, sendo destacado que, somente com a pressão exercida pelos representantes e movimentos sociais aos órgãos responsáveis, é possível efetivar uma mudança na política pública da habitação, reiterando que a metodologia participativa pode ser 
entendida como o instrumento necessário à garantia da qualidade e adequação do projeto à proposta.

\begin{abstract}
Mas até hoje ainda não se conseguiu encontrar uma solução pra algumas coisas, pois se mandamos um projeto diferente do que se impõe, ele será reprovado, com certeza. Então eu aproveito que vocês [líderes comunitários] estão aqui e digo que os movimentos precisam levar essas reivindicações nas conferências e representações, só assim a gente consegue mudar essa tipologia, porque vocês tem muito mais força nisso que a gente. (Técnico da Secretaria Municipal de Habitação - SEMHAB/JP, em 30 de Abril de 2013)
\end{abstract}

Assim, tanto no discurso dos representantes comunitários quanto no dos técnicos a padronização da solução adotada pela iniciativa pública, é reincidente a necessidade de diversificar as estratégias quanto à dinâmica social. Em ambos os discursos, apontam-se para a inadequação da tipologia quanto à localização, implantação, dimensionamento, uso, cultura, inflexibilidade, padronização excessiva e inadequação dos espaços criados à dinâmica dos moradores.

\title{
5 CONSIDERAÇÕES FINAIS
}

Em resposta às diversas avaliações da tipologia habitacional aplicada pela iniciativa pública à população de baixa renda, um conflito significativo entre as necessidades dos usuários e a resposta arquitetônica concebida é verificado. Há um descompasso entre as demandas, as necessidades do público e a concretização destas, expressa na tipologia do projeto.

Neste estudo foi observado que a incompatibilidade da unidade habitacional decorrente da não-observância de geração de renda prejudica a subsistência do núcleo familiar. A localização dos conjuntos e seu distanciamento dos pontos de comércio ou trabalho continuam sendo citadas como problemas da política habitacional de governo.

Verificou-se também que a uniformização das soluções, com informações cadastrais limitadas dos beneficiários, subdimensionadas, e as falhas na execução da política habitacional (como o perfil do usuário na fase final de desenvolvimento projetual) dificultam a concepção de soluções tipológicas diversificadas.

Essas constatações ratificam a necessidade de repensar o atual padrão da habitação social, não apenas quanto ao produto, mas quanto à reformulação do próprio processo projetual. Portanto, corrobora-se com prerrogativa de se envolver as entidades de representação no processo projetual participativo, como atividade necessária.

A opinião dos moradores é de suma importância à sinalização dos principais aspectos a serem considerados no desenvolvimento da tipologia arquitetônica, podendo o usuário ser interpretado enquanto sinalizador da qualidade e adequação do projeto. Assim, fazse necessária a garantia da incorporação destas variáveis ao processo projetual, pelo ensejo de participação efetiva da população, não restrita somente à intervenção nas soluções adotadas na conclusão do projeto, enquanto instrumento de legitimação da proposta, mas assegurando o poder de decisão da população quanto às estratégias desenvolvidas.

A adoção de iniciativas de participação da população deve-se não apenas se destinar à legitimação do projeto, mas sim, incorporar as demandas daqueles que deverão usufruir do projeto - não apenas quando o programa já se encontra em fase de conclusão. Logo, é importante a inserção da comunidade em todo o processo projetual, para integração de interesses e avaliação contínua, com o objetivo de elaborar, de forma conjunta, uma tipologia habitacional adequada às necessidades e especificidades do público. 


\section{REFERÊNCIAS}

ALCÂNTARA, E. MONTEIRO, C. Em que a Vida na Favela é melhor que em um Conjunto de Apartamentos? O caso de Abençoada por Deus, Recife. In: Encontro Nacional da Anppas, n.5, 2010, São Paulo. Anais. Florianópolis: Universidade Federal de Santa Catarina - UFSC, 2010.

BORBA, S. F. S. Análise dos Espaços Livres em conjuntos habitacionais do Programa Minha Casa Minha Vida. [trabalho de conclusão de curso]. João Pessoa: Universidade Federal da Paraíba, Curso de Arquitetura e Urbanismo; 2014.

BRASIL, Lei ${ }^{\circ}$ 11.977, de 07 de Julho de 2009. Dispõe sobre o Programa Minha Casa Minha Vida - PMCMV e a regularização fundiária de assentamentos localizados em áreas urbanas. Diário Oficial da União. Brasília, DF, 08 jul. 2009. Seção 1, p.1.

DEL RIO, V. IWATA, N. SANOFF, H. Programação e Métodos Participativos para o Projeto de Arquitetura: o caso do Colégio de Aplicação da UFRJ. In: Seminário Internacional NUTAU, n.8, 2000, São Paulo. Anais. São Paulo: Universidade de São Paulo - FAU/USP, 2000.

DUARTE, F. CONCEIÇÃO, C. CORDEIRO, C. LIMA, F. A integração das necessidades de usuários e projetistas como fonte de inovação para o projeto. Rio de Janeiro: Universidade Federal do Rio de Janeiro - UFRJ, 2008, p.59-71.

FREITAS, E. L.H. Como qualificar conjuntos habitacionais populares. Brasília: Caixa Econômica Federal, 2004. 200p.

GRANATH, J. A. Architecture - Participation of users in design activities. Göteborg: Chalmers Tekniska Högskola, 2001.

JENSEN, P. A. Continuous Briefing in Building Projects. Lyngby: Technical University of Denmark, 2006.

MALARD, M. L. CONTI, A. SOUZA, R. C. F. CAMPOMORI, M. K. J. Avaliação PósOcupação, Participação dos Usuários e Melhoria da Qualidade de Projetos Habitacionais: uma Abordagem Fenomenológica. Belo Horizonte: Universidade Federal de Minas Gerais UFMG, 2002. 